\title{
Which LDL Value Should Clinicians Look at?
}

\author{
Harshad Malve ${ }^{1}$ Amit Asalkar² \\ ${ }^{1}$ Department of Pharmacology, Vedanta Institute of Medical \\ Sciences, Sasvand, Dhundalwadi, Dahanu, Maharashtra, India \\ ${ }^{2}$ Hormo-Care and Consultant Endocrinologist, Aster Aadhar \\ Hospital, Kolhapur, Maharashtra, India \\ J Lab Physicians 2021;13:129-133.
}

\begin{abstract}
Address for correspondence Harshad Malve, MBBS, MD, Department of Pharmacology, Vedanta Institute of Medical Sciences, Sasvand, Dhundalwadi, Dahanu 401606, Maharashtra, India (e-mail:dr.harshad.malve@gmail.com).
\end{abstract}

\begin{abstract}
Keywords

- hyperlipidemia

- direct LDL estimation

- Friedewald's formula

- LDL cholesterol

Objectives LDL cholesterol is routinely estimated by the Friedewald formula to guide the treatment of dyslipidemia. However, Friedewald equation has certain limitations, especially with high triglyceride levels. Direct methods are available for LDL estimation but have received relatively little scrutiny in the Indian setting. This study was aimed at comparing the calculative and direct methods of LDL estimation in Indian hyperlipidemic patients.

Materials and Methods In this observational study, data from 380 consecutive lipid profiles of patients visiting a tertiary care hospital in Mumbai were analyzed retrospectively. CHOD PAP method was used to estimate total cholesterol. Enzymatic colorimetric method was used to estimate triglycerides. Enzyme selective protection method was used to estimate HDL. Direct LDL was estimated by homogenous enzymatic colorimetric assay and very low-density lipoprotein was calculated, whereas Friedewald's formula was used to derive calculated LDL.

Results Total cholesterol values correlated positively with the LDL values measured by both methods. However, a statistically significant difference was noted between the correlation coefficients of both the methods. Triglyceride values correlated weakly with the LDL levels measured by both the methods. A weak negative correlation was observed with LDL by the calculated method, whereas a weak positive correlation existed between TG and LDL by the direct method. The difference between the correlation coefficients was statistically significant.

Conclusion Both direct and calculated methods of LDL estimation have their limitations. A robust study with a larger sample size is needed to further investigate whether the differences in the different LDL estimation methods can translate to "clinical relevance" in the Indian setting.
\end{abstract}

\section{Introduction}

Robust clinical evidence supports the fact that elevated level of low-density lipoprotein cholesterol (LDL-C) is an independent risk factor for coronary artery disease (CAD).$^{1-3}$ This has led to an understanding that lowering LDL-C is one of the key therapeutic targets in patients with CAD or those at a

published online May 26, 2021
DOI https://doi.org/ $10.1055 / \mathrm{s}-0041-1729131$ ISSN 0974-2727 risk of developing it. Dietary changes, lifestyle modification, and drug therapy to lower LDL-C can considerably reduce the morbidity and mortality associated with cardiovascular disorders, particularly CAD. ${ }^{4-6}$ Given the crucial role played by LDL-C in etiopathogenesis and clinical management of CAD, laboratorial measurements of LDL-C have assumed paramount importance in its diagnosis and monitoring,

(c) 2021. The Indian Association of Laboratory Physicians

This is an open access article published by Thieme under the terms of the Creative Commons Attribution-NonDerivative-NonCommercial-License, permitting copying and reproduction so long as the original work is given appropriate credit. Contents may not be used for commercial purposes, or adapted, remixed, transformed or built upon. (https://creativecommons.org/licenses/by-nc-nd/4.0/). Thieme Medical and Scientific Publishers Pvt. Ltd. A-12, 2nd Floor, Sector 2, Noida-201301 UP, India 
particularly in patients presenting with hyperlipidemia or dyslipidemia.?

Different methods have been established for the measurement of LDL-C, each having their pros and cons. LDL-C measured by ultracentrifugation is recommended by Lipid Research Clinic. ${ }^{8}$ Bioquantification low-density lipoprotein (BQ-LDL) has also been recommended as a standard technique for LDL-C estimation for measuring LDL-C. However, this method could not gain popularity at ground level due to several shortcomings. As a laboratory method, BQ-LDL is expensive, labor intensive, and is not freely available..$^{9,10}$ Therefore, most laboratories prefer to use the indirect method of LDL-C estimation, also called the Friedewald method. ${ }^{11,12}$ Under this method, laboratory values for triglycerides (TGs) and total cholesterol (TC) are utilized to arrive at an indirect estimation of LDL-C. The TG and TC values are fed into the Friedewald formula (FF) to yield LDL-C values. This method is widely used for LDL-C estimation even today. However, several concerns have been expressed with the use of this method. ${ }^{11,12}$

To begin with, this method is based on the postulate that a constant nondynamic correlation exists between TG/TC and LDL-C. Hence, TG and TC values can be extrapolated for LDL-C calculations. However, evidence has shown that this may not hold true for all clinical situations and scenarios and might adversely impact LDL-C calculations. ${ }^{12-14}$ Besides, combining TG, TC, and LDL-C values gives rise to significant analytical variability. ${ }^{12-14}$ Clinically, the most noteworthy limitation of the indirect method is that FF cannot be applied to samples with TG levels above $400 \mathrm{mg} / \mathrm{d}$. Also, FF cannot be used in patients with dysbetalipoproteinemia (type III hyperlipoproteinemia) and when chylomicrons are present.

Hence, if LDL-C is to be estimated by the indirect method, the clinician is left with no choice but to opt for a fasting sample. This limits the postprandial assessment and is also cumbersome for the patient. ${ }^{12-14}$

Given these limiting factors of the indirect method of LDL estimation, a need was felt to improvise the laboratory technique for LDL-C measurement. Hence, several commercially available assays have been developed for the direct measurement of LDL-C. Numerous such commercial assay kits are available and currently used. Direct estimation of LDL-C represents the third generation of laboratory techniques for LDL-C estimation. ${ }^{12}$ However, discrepancies have been reported between LDL-C values calculated using the FF and those obtained by direct assays. ${ }^{15-18}$ These discrepancies are of notable concern as some laboratories continue to use the FF method whereas others have shifted to the direct method. The discrepancy between LDL-C estimates obtained by the two methods is further augmented if the two methods are used interchangeably. This can triggerconfusions and misinterpretations, particularly while stratifying patients into high- and low-risk groups during the process of therapy decision-making and therapeutic monitoring. ${ }^{19,20}$

There is very limited data comparing the direct method for LDL estimation with the FF method, particularly in Indian patients with hyperlipidemia. Hence, this study was conducted to compare the calculative (FF method) and direct methods of LDL-C estimation at given TC and TG values in selected Indian population.

\section{Materials and Methods}

This study uses observational data from 380 consecutive lipid profiles done at a laboratory in Mumbai, Maharashtra, which is certified by the International Organization for Standardization and accredited by the College of American Pathologists and the National Accreditation Board for Testing and Calibration Laboratories. The data was collected from October 2008 to January 2009. Institutional Ethics Committee's permission was obtained prior to the study.

Patients aged 18 to 65 years with hyperlipidemia attending the cardiology outpatient department at a tertiary care hospital in Mumbai were screened. During the screening, a general clinical examination was done and blood samples were collected for lipid profile after their informed consent was taken. The lipid profile included serum levels of LDL-C, high-density lipoprotein cholesterol (HDL-C), TC, TG, and very low-density lipoprotein cholesterol (VLDL-C). All investigations were done at an accredited laboratory. LDL-C was measured by the calculated method using FF and by the direct method.

Most parameters in lipid profile were estimated by photometric technology. CHOD PAP method (mode of reaction: end point; linearity: $600 \mathrm{mg} / \mathrm{dL}$ ) was used to estimate TC. ${ }^{21}$ Enzymatic colorimetric method GPO PAP was used to estimate TG. ${ }^{22}$ Enzyme selective solubilization method (mode of reaction: end point; linearity: $150 \mathrm{mg} / \mathrm{dL}$ ) was used to estimate HDL. ${ }^{23}$ Homogenous enzymatic colorimetric assay with rapid reagent kit (mode of reaction: differential; linearity: $700 \mathrm{mg} / \mathrm{dL}$ ) was used to estimate direct LDL. ${ }^{23}$ Commercial kits from Agappe were used for testing TC, HDL-C, and direct LDL-C. Calibrators received with the testing kits were used for the assay. Stringent internal quality control checks were performed regularly.

VLDL was calculated as follows: VLDL $=\mathrm{TG} / 5$. LDL-C readings were derived by $\mathrm{FF}$ as follows: $\mathrm{LDL}-\mathrm{C}=$ [TC]-[HDL-C]-[TG/5]. ${ }^{11}$

\section{Statistical Analysis}

Descriptive statistics means, standard deviations (SDs), and covariance were calculated with Microsoft Excel. Data was reported as mean $\pm \mathrm{SD}$. Linear regression and paired $t$-test were used. Mean values for LDL-C by the two methods were compared by paired students' $t$-tests. Linear relationships were determined from the standard Pearson correlation coefficients by linear regression analyses using SPSS (VER 10.0).

\section{Results}

Mean age of patients was $40.20 \pm 9.06$ years with a mean weight of $62.76 \pm 11.63 \mathrm{kgs}$ and body mass index of $25.12 \pm$ 3.24. The male to female ratio was $1: 2.6$.

For the purpose of data analysis, TG values of the study patients were stratified into three ranges: 1 to 100,101 to 200, and 201 to 400 (mg/dL). Similarly, TC values were 
also stratified into the following three ranges: 100 to 200 , 201 to 250 , and $>250(\mathrm{mg} / \mathrm{dL})$. The correlation of TC and TG values with LDL measured by both the methods was also analyzed without categorizing the TC and TG values into different ranges. In this case, the TC and TG values were considered as whole unstratified datasets. Correlation of TG levels with LDL values measured through the direct and calculated methods is mentioned in - Table 1. Correlation of TC levels with LDL values measured through the direct and calculated methods is mentioned in - Table 2 . Correlation between TC and LDL values when LDL is measured by the direct as well as the calculated method is mentioned in - Table 3. Correlation between TG and LDL values when LDL is measured by the direct as well as the calculated method is mentioned in - Table 4 . The mean LDL values obtained through both the methods are mentioned in - Table 5 .
The study data presented here explores how the dynamics of the clinical correlation between TG/TC and LDL is impacted with a change in the method of measurement of LDL (calculated or direct).

In the TG ranges of 1 to 100 and 101 to $200 \mathrm{mg} / \mathrm{dL}$, a statistically significant difference was noted in the correlation of TG values with LDL values depending upon the method of LDL measurement. This difference was not seen in the TG value range above $201 \mathrm{mg} / \mathrm{dL}$. Similarly, in the TC range of 100 to $200 \mathrm{mg} / \mathrm{dL}$, a statistically significant difference was not noted in the correlation of TC with LDL-C and low-density lipoprotein-direct (LDL-D) values. However, TC values above $200 \mathrm{mg} / \mathrm{dL}$ show a statistically significant difference in their correlation with LDL-C and LDL-D. A statistically significant difference was also noted between the overall mean LDL values obtained through the direct and the calculated methods.

The discrepancy in LDL-C measurements between the

Table 1 Correlation of TG levels with LDL values measured through the direct and calculated methods

\begin{tabular}{|l|l|l|l|l|}
\hline $\begin{array}{l}\text { TG range } \\
(\mathrm{mg} / \mathrm{dL})\end{array}$ & $\boldsymbol{n}$ & $\begin{array}{l}\text { Mean } \pm \text { SD } \\
\text { LDL-C }(\mathbf{m g} / \mathrm{dL})\end{array}$ & $\begin{array}{l}\text { Mean } \pm \text { SD } \\
\text { LDL-D }(\mathbf{m g} / \mathrm{dL})\end{array}$ & $\begin{array}{l}p \text {-Value } \\
(95 \% \mathrm{CI})\end{array}$ \\
\hline $1-100$ & 123 & $143.90 \pm 20.27$ & $137.71 \pm 19.16$ & $0.0146(1.22-11.13)^{\mathrm{a}}$ \\
\hline $101-200$ & 195 & $148.77 \pm 20.85$ & $144.27 \pm 17.26$ & $0.0208(0.68-8.31)^{\mathrm{a}}$ \\
\hline $201-400$ & 62 & $142.47 \pm 25.68$ & $145.67 \pm 19.80$ & $0.3829(10.42-0.43)$ \\
\hline
\end{tabular}

Abbreviations: Cl, confidence interval; LDL-C, low-density lipoprotein calculated; LDL-D, low-density lipoprotein-direct; TG, triglyceride. Notes: Two-tailed $p$-values have been calculated. Both $p$-values marked with "a" are statistically significant as per conventional criteria.

Table 2 Correlation of TC levels with LDL values measured through the direct and calculated methods

\begin{tabular}{|l|l|l|l|l|}
\hline $\begin{array}{l}\text { TC range } \\
(\mathbf{m g} / \mathbf{d L})\end{array}$ & $\boldsymbol{n}$ & $\begin{array}{l}\text { Mean } \pm \text { SD } \\
\text { LDL-C }(\mathbf{m g} / \mathbf{d L})\end{array}$ & $\begin{array}{l}\text { Mean } \pm \text { SD } \\
\text { LDL-D }(\mathbf{m g} / \mathbf{d L})\end{array}$ & $\begin{array}{l}p \text {-Value } \\
(95 \% \mathrm{Cl})\end{array}$ \\
\hline $100-200$ & 62 & $116.60 \pm 12.61$ & $118.52 \pm 12.41$ & $0.3933(6.37-2.52)$ \\
\hline $201-250$ & 270 & $147.45 \pm 13.92$ & $143.68 \pm 12.57$ & $0.0010^{\text {a }}(1.52-6.01)$ \\
\hline$>250$ & 42 & $177.15 \pm 17.74$ & $165.88 \pm 18.60$ & $0.0031^{\text {a }}(3.89-18.62)$ \\
\hline
\end{tabular}

Abbreviations: Cl, confidence interval; LDL-C, low-density lipoprotein calculated; LDL-D, low-density lipoprotein-direct; TC, total cholesterol. Notes: Two-tailed $p$-values have been calculated. Both $p$-values marked with "a" are statistically significant as per conventional criteria.

Table 3 Correlation between TC and LDL values when LDL is measured by the direct as well as calculated method

\begin{tabular}{|l|l|l|}
\hline $\begin{array}{l}\text { Type of LDL } \\
\text { measurement }\end{array}$ & $\begin{array}{l}\text { Correlation } \\
\text { co-efficient }(r)\end{array}$ & $p$-Value \\
\hline LDL-C & 0.86074 & 0.0418 \\
\hline LDL-D & 0.81708 & \\
\hline
\end{tabular}

Abbreviations: LDL-C, low-density lipoprotein calculated; LDL-D, low-density lipoprotein-direct; $r$, co-efficient of correlation; TC, total cholesterol.

Table 4 Correlation between TG and LDL values when LDL is measured by the direct as well as calculated method

\begin{tabular}{|l|l|l|}
\hline $\begin{array}{l}\text { Type of LDL } \\
\text { measurement }\end{array}$ & $\begin{array}{l}\text { Correlation } \\
\text { co-efficient }(r)\end{array}$ & $p$-Value \\
\hline LDL-C & $0.0506^{\text {a }}$ & 0.009424 \\
\hline LDL-D & $0.13758^{\mathrm{a}}$ & \\
\hline
\end{tabular}

Abbreviations: LDL-C, low-density lipoprotein-calculated; LDL-D, low-density lipoprotein-direct; $r$, co-efficient of correlation; TG, triglyceride. Note: Weak correlation marked with ${ }^{\text {. }}$.
Table 5 The mean LDL values obtained through both methods

\begin{tabular}{|l|l|l|l|}
\hline LDL type & $\boldsymbol{n}$ & $\begin{array}{l}\text { Mean } \pm \text { SD } \\
\text { LDL-C }(\mathrm{mg} / \mathrm{dL})\end{array}$ & $\begin{array}{l}\boldsymbol{p} \text {-Value } \\
(95 \% \mathrm{Cl})\end{array}$ \\
\hline LDL-C & 380 & $146.17 \pm 21.64$ & $\begin{array}{l}0.0098 \\
(0.92-6.66)\end{array}$ \\
\hline
\end{tabular}

Abbreviations: LDL-C, low-density lipoprotein-calculated; LDL-D, low-density lipoprotein-direct; $n$, number of observations.

two methods was also statistically significant ( $p=0.0098$ ) when the entire study data was analyzed as a single unstratified dataset. TC values correlated positively with LDL values measured by both the methods. However, a statistically significant difference ( $p=0.0418$ ) was noted between the correlation coefficients of both the methods. TG values correlated weakly with LDL levels measured by both the methods. A weak negative correlation was observed with LDL-C, whereas a weak positive correlation existed between TG and 
LDL-D values. The difference between the correlation coefficients was statistically significant.

\section{Discussion}

In 2002, Nauck and colleagues published a review which analyzed various studies comparing the calculated and direct methods of LDL estimation. They concluded that the direct method of LDL estimation should be recommended to supplement the FF, particularly in cases where the calculation is known to be unreliable, for example, where TGs $>4,000 \mathrm{mg} / \mathrm{L}^{24}$ Miller et al have mentioned seven direct methods for measuring HDL and LDL cholesterol. However, comparative studies between them are not available. ${ }^{25}$

Recently, Warade and colleagues found that the calculated method of LDL estimation underestimates values at lower levels of LDL and higher levels of TG as compared with the direct method. Our study substantiates the same. ${ }^{26}$ Sahu and colleagues have compared these two methods of LDL estimation earlier, which was published in 2005. They showed that a significant difference exists in the mean LDL-C levels obtained by the two methods at TG levels $<200 \mathrm{mg} / \mathrm{dL}$ $(p<0.02)$ and TC levels $>150 \mathrm{mg \%} .^{27}$ These findings are consistent with the results obtained in the present study. Kannan and colleagues compared the findings from the FF and direct methods from an Indian laboratory database. They suggested repeating the LDL by direct assay techniques, particularly in patients with $\mathrm{TG}>200 \mathrm{mg} / \mathrm{dL}$ and when $\mathrm{LDL}<70$ or $>$ $130 \mathrm{mg} / \mathrm{dL} .{ }^{28}$ However, it may not be a cost-effective option. ${ }^{29}$

Nevertheless, the present study has its own limitations. The study data tested the statistical significance of the difference between the direct and indirect methods of LDL-C estimation. However, the study did not investigate further whether this "statistical significance" translated into "clinical relevance." This leaves us with a couple of unanswered questions: Is the statistically significant difference between the two methods of LDL-C estimation a clinically meaningful or relevant difference? Does a statistically significant difference between the two methods also imply that this difference could have a cognizable impact on therapy decision-making, monitoring, and prognostication? Perhaps the statistically significant differences between the two arms of a clinical study should be investigated further to understand their clinical impact, to make a clinical recommendation in favor of any one of the study arms. With the recent controversy surrounding lipid levels and its clinical significance, we need to be sure of using the right technique without spending excess money from the patients' pocket. ${ }^{30}$

With respect to study design, the sample size of the study was limited to arrive at any robust conclusion as to which of the two methods is superior for LDL-C estimation. Besides, to ascertain which of these two methods is more robust, it is imperative to compare both with an accepted standard method. The current study involves a comparison between the two methods only and does not compare the two methods with a third standard reference method; thus, a comment cannot be made vis-à-vis the accuracy of the rate of detection, sensitivity, and specificity of the two methods being compared. This study does not have LDL-C estimations made by the modified FF equation, Martin/Hopkins estimation, or Anandraja's formula. All these new methods can be tested together to get robust results. ${ }^{31-33}$ These limitations need to be taken into account while designing future clinical studies for such a comparison. Future clinical studies need to involve a larger sample size and be adequately powered to test the difference between multiple methods. A reference standard needs to be incorporated into the study design so that the different methods of LDL-C estimation can be compared against this standard technique. The study population should perhaps involve more heterogeneous subgroups of dyslipidemic patients, for example, those with mild, moderate, and severe hypertriglyceridemia and hypercholesterolemia. Perhaps a prospective study comparing all the methods mentioned so far, with a larger sample size and heterogeneous patient subgroups, may yield more robust information. Moreover, we need to find out which is the more cost-effective and accurate method for estimating LDL in the Indian setting.

\section{Permissions}

All relevant permissions were taken. Institutional Ethics Committee's approval was taken.

\section{Authors' Contribution}

H.M. searched literature and conceived the study. H.M. was involved in protocol development, gaining ethical approval, patient recruitment, and data analysis. H.M. wrote the first draft of the manuscript. A.A. gave inputs on results and expert opinion on discussion. A.A. provided valuable suggestions on answering queries from the journal and creating a revised version. Both H.M. and A.A. reviewed and edited the manuscript and approved the final version of the manuscript. The guarantor for this document is H.M.

\section{Funding Support}

None.

\section{Conflict of Interest}

None declared.

\section{Acknowledgment}

None.

\section{References}

1 Gordon T, Kannel WB, Castelli WP, Dawber TR. Lipoproteins, cardiovascular disease, and death. The Framingham study. Arch Intern Med 1981;141(9):1128-1131

2 Grundy SM. Role of low-density lipoproteins in atherogenesis and development of coronary heart disease. Clin Chem 1995;41(1):139-146

3 Kannel WB, Nekton JD, Wentworth D, et al. Overall and coronary heart disease mortality rates in relation to major risk factors in 325,348 men screened for the MRFIT. Multiple risk factor intervention trial. Am Heart J 1986;112(4):825-836

4 The lipid research clinics coronary primary prevention trial results. II. The relationship of reduction in incidence of coronary heart disease to cholesterol lowering. JAMA 1984;251(3):365-374 
5 Scandinavian Simvastatin Survival Study Group. Randomised trial of cholesterol lowering in 4444 patients with coronary heart disease: the Scandinavian Simvastatin Survival Study (4S) Lancet 1994;344(8934):1383-1389

6 Sacks FM, Pfeffer MA, Moye LA, et al. The effect of pravastatin on coronary events after myocardial infarction in patients with average cholesterol levels. Cholesterol and recurrent events trial investigators. N Engl J Med 1996;335(14):1001-1009

7 Delport R. The value of accurate analytics in the management of cardiovascular disease. Cardiovasc J S Afr 2006;17(1):3-5

8 Cathcart S, Dominiczak MH. The measurement of lipoprotein subfractions in plasma using a tabletop ultracentrifuge. Ann Clin Biochem 1990;27(Pt 5):459-464

9 DeLong DM, DeLong ER, Wood PD, Lippel K, Rifkind BM. A comparison of methods for the estimation of plasma low- and very low-density lipoprotein cholesterol. The Lipid Research Clinics Prevalence Study. JAMA 1986;256(17):2372-2377

10 Bachorik PS, Ross JW. The National Cholesterol Education Program Working Group on Lipoprotein Measurement. National Cholesterol Education Program recommendations for measurement of low-density lipoprotein cholesterol: executive summary. Clin Chem 1995;41(10):1414-1420

11 Friedewald WT, Levy RI, Fredrickson DS. Estimation of the concentration of low-density lipoprotein cholesterol in plasma, without use of the preparative ultracentrifuge. Clin Chem 1972;18(6):499-502

12 Amayo AA, Kirera S. Comparison of calculated and direct low density lipoprotein cholesterol determinations in a routine laboratory. East Afr Med J 2004;81(3):154-158

13 Rifai N, Warnick GR, McNamara JR. Belcher JD, Grinstead GF, Frantz ID Jr. Measurement of low-density-lipoprotein cholesterol in serum: a status report. Clin Chem 1992;38(1):150-160

14 McNamara JR, Cohn JS, Wilson PW, Schaefer EJ. Calculated values for low-density lipoprotein cholesterol in the assessment of lipid abnormalities and coronary disease risk. Clin Chem 1990;36(1):36-42

15 Matas C, Cabré M, La Ville A, et al. Limitations of the Friedewald formula for estimating low-density lipoprotein cholesterol in alcoholics with liver disease. Clin Chem 1994;40(3):404-406

16 Maitra A, Hirany SV, Jialal I. Comparison of two assays for measuring LDL cholesterol. Clin Chem 1997;43(6 Pt 1):1040-1047

17 Esteban-Salán M, Guimón-Bardesi A, de La Viuda-Unzueta JM, Azcarate-Ania MN, Pascual-Usandizaga P, Amoroto-Del-Río E. Analytical and clinical evaluation of two homogeneous assays for LDL-cholesterol in hyperlipidemic patients. Clin Chem 2000;46(8 Pt 1):1121-1131

18 Harris N, NeufeldEJ, NewburgerJW, etal.Analytical performance and clinical utility of a direct LDL-cholesterol assay in a hyperlipidemic pediatric population. Clin Chem 1996;42(8 Pt 1): 1182-1188

19 Schectman G, Patsches M, Sasse EA. Variability in cholesterol measurements: comparison of calculated and direct LDL cholesterol determinations. Clin Chem 1996;42(5):732-737
20 Krause BR, Schork NJ, Kieft KA, Smith MP, Maciejko JJ. High correlation but lack of agreement between direct high-performance gel chromatography analysis and conventional indirect methods for determining lipoprotein cholesterol. Clin Chem 1996;42(12):1996-2001

21 Allain CC, Poon LS, Chan CS, Richmond W, Fu PC. Enzymatic determination of total serum cholesterol. Clin Chem 1974;20(4):470-475

22 Trinder P. Triglyceride estimation by GPO-PAP method. Ann Clin Chem 1969;6:24-27

23 Belcher JD, McNamara JR, Grinstead GF, et al. Measurement of low-density lipoprotein cholesterol concentration. In: Rifai N, Warnick GR, eds. Methods for Clinical Laboratory Measurements of Lipid and Lipoprotein Risk Factors. Washington, DC: AACC Press; 1991 75-86

24 Nauck M, Warnick GR, Rifai N. Methods for measurement of LDL-cholesterol: a critical assessment of direct measurement by homogeneous assays versus calculation. Clin Chem 2002;48(2):236-254

25 Miller WG, Myers GL, Sakurabayashi I, et al. Seven direct methods for measuring HDL and LDL cholesterol compared with ultracentrifugation reference measurement procedures. Clin Chem 2010;56(6):977-986

26 Warade JP, Dahake H, Kavitha R. Comparison between direct estimation of LDL and Friedewald's formula. IAIM 2016;3(2):10-17

27 Sahu S, Chawla R, Uppal B. Comparison of two methods of estimation of low density lipoprotein cholesterol, the direct versus Friedewald estimation. Indian J Clin Biochem 2005;20(2):54-61

28 Kannan S, Mahadevan S, Ramji B, Jayapaul M, Kumaravel V. LDL-cholesterol: Friedewald calculated versus direct measurement-study from a large Indian laboratory database. Indian J Endocrinol Metab 2014;18(4):502-504

29 Malve H. Comparison of direct versus Friedewald estimation of low density lipoprotein cholesterol in Indian patients: cost-effectiveness concerns? Indian J Endocrinol Metab 2015;19(3):436

30 Unruh L, Rice T, Rosenau PV, Barnes AJ. The 2013 cholesterol guideline controversy: would better evidence prevent pharmaceuticalization? Health Policy 2016;120(7):797-808

31 Palmer MK, Barter PJ, Lundman P, Nicholls SJ, Toth PP, Karlson BW. Comparing a novel equation for calculating low-density lipoprotein cholesterol with the Friedewald equation: a VOYAGER analysis. Clin Biochem 2019;64:24-29

32 Martin SS, Giugliano RP, Murphy SA, et al. Comparison of low-density lipoprotein cholesterol assessment by Martin/ Hopkins estimation, Friedewald estimation, and preparative ultracentrifugation: insights from the Fourier trial. JAMA Cardiol 2018;3(8):749-753

33 Krishnaveni P, Gowda VM. Assessing the validity of Friedewald's formula and Anandraja's formula for serum LDLcholesterol calculation.J Clin Diagn Res 2015;9(12):BC01-BC04 